\title{
Effects of platinum content on tribological properties of platinum/nitrogen doped diamond-like carbon thin films deposited via magnetron sputtering
}

\author{
Nay Win KHUN, Erjia LIU* \\ Received: 12 October 2013 / Revised: 22 December 2013 / Accepted: 25 January 2014 \\ (C) The author(s) 2014. This article is published with open access at Springerlink.com
}

School of Mechanical and Aerospace Engineering, Nanyang Technological University, 50 Nanyang Avenue, Singapore 639798, Singapore

\begin{abstract}
Platinum (Pt) and nitrogen $(\mathrm{N})$ were co-incorporated in diamond-like carbon (DLC) thin films using a magnetron sputtering system to form PtN-DLC thin films for tribological applications. The Pt content in the PtN-DLC films prepared on Si substrates was controlled by varying RF power applied to a $\mathrm{Pt}$ target at a fixed $\mathrm{N}_{2}$ flow rate. The tribological properties of the PtN-DLC films were investigated with respect to the Pt content in the films. The uncoated Si substrate surface tested against a steel ball of $6 \mathrm{~mm}$ in diameter had significant abrasive and fatigue wear, while no significant wear was found on the N-DLC coated sample surface, indicating that the N-DLC film effectively prevented its underlying Si substrate from wear. However, the incorporation of $\mathrm{Pt}$ in the N-DLC films reduced the wear resistance of the films by degrading $\mathrm{sp}^{3}$-bonded cross-linking structures of the films so that significant wear tracks were found on the surfaces of the PtN-DLC films. Therefore, the increased radio frequency (RF) power applied to the Pt target decreased the wear resistance of the PtN-DLC films as a result of the increased Pt content.
\end{abstract}

Keywords: diamond-like carbon (DLC) film; Pt and N doping; friction; wear

\section{Introduction}

Diamond-like carbon (DLC) is well known as a preferred material for tribological applications since it exhibits high hardness, high wear resistance, and very low friction [1]. DLC films are suitable as protective coatings for a number of applications such as heart valves, hip and knee joints, inkjet printers, magnetic hard discs, and microfluidic devices [2]. Si wafers are commonly used to make microfluidic devices or secondary micromolds because of their favorable surface smoothness. However, the lifetime of Si micromolds has been significantly impacted by their high brittleness and friction. DLC films have thus been considered as protective coatings to extend the lifetime of Si micromolds [2].

* Corresponding author: Erjia LIU.

E-mail: MEJLiu@ntu.edu.sg
High residual stress of DLC films can result in a poor adhesion strength of the films, which in turn leads to easy delamination of the films from their substrates. A promotion in the adhesion strength of DLC films is an effective way to improve the antiwear performance of the films without any significant adhesive failure in service. It was reported that introduction of nitrogen (N) into DLC films promoted the adhesion strength of the films and gave rise to a lubricating effect reducing the friction of the films [3-5]. In addition, incorporation of metals, such as nickel (Ni), aluminum ( $\mathrm{Al}$ ) and so on, in DLC films could improve the adhesion strength of the films by degrading $\mathrm{sp}^{3}$-bonded cross-linking structures of the films, which were responsible for high residual stresses in the films [6-8]. Recently, Khun et al. reported that the co-incorporation of $\mathrm{N}$ and PtRu in DLC films resulted in the improved adhesion strength of the films [5, 9-12]. In addition, the tribological properties 
of PtRuN-DLC films were unsatisfactorily investigated with respect to carbon sputtering power and film thickness to support the adhesion results of the films $[10,11]$. However, the effect of noble metal content on the tribological properties of PtRuN-DLC films has not been reported yet. Further, Pt incorporated N-DLC thin films for tribological applications have not been reported either. Therefore, an investigation on the tribological properties of PtN-DLC thin films with respect to Pt content is necessary to understand a correlation between the chemical composition of the DLC films and their tribological properties.

In this study, $\mathrm{Pt}$ and $\mathrm{N}$ were co-incorporated into DLC films via magnetron sputtering deposition to form PtN-DLC thin films. The Pt content in the PtNDLC films was controlled by varying RF power applied to the $\mathrm{Pt}$ target at a fixed $\mathrm{N}_{2}$ flow rate. The tribological behavior of the PtN-DLC films was systematically investigated using ball-on-disc micro-tribological test and the chemical composition and bonding structure of the films were studied using X-ray photoelectron spectroscopy (XPS) and micro-Raman spectroscopy, respectively.

\section{Experimental details}

PtN-DLC thin films were deposited on conductive p-Si(100) (0.001-0.0035 $\Omega \cdot \mathrm{cm})$ substrates using a magnetron sputtering deposition system (Penta Vacuum) by varying RF power from 20 to $60 \mathrm{~W}$ applied to a Pt target (99.995 at\%) of 3 inch in diameter. Prior to film deposition, the $\mathrm{Si}$ substrates were cleaned with ethanol in an ultrasonic bath for 20 min followed by deionized (DI) water cleaning and air drying. The Si substrates were further cleaned by $\mathrm{Ar}^{+}$plasma in the deposition chamber at a pressure of 10 mTorr and a substrate bias of $-250 \mathrm{~V}$ for $20 \mathrm{~min}$ to remove the oxide layers and contaminants on the substrate surfaces. For all the film depositions, direct current (DC) power applied to a graphite target $(99.999 \%$ C) of 3 inch in diameter, working pressure, substrate bias, substrate rotation speed and $\mathrm{N}_{2}$ and $\mathrm{Ar}$ gas flow rates were fixed at $750 \mathrm{~W}, 4 \mathrm{mTorr},-20 \mathrm{~V}, 20 \mathrm{rpm}, 5 \mathrm{sccm}$ and $50 \mathrm{sccm}$, respectively. Although all the film depositions were carried out at room temperature $\left(\mathrm{RT} \sim 22-24{ }^{\circ} \mathrm{C}\right)$, the substrate temperature reached approximately $38^{\circ} \mathrm{C}$ during the deposition.

XPS (Kratos-Axis Ultra) was employed to measure the chemical compositions of the films with pass energies of $40 \mathrm{eV}$ for narrow scans and $160 \mathrm{eV}$ for wide scans. The X-ray source used was a monochromatic $\mathrm{Al} \mathrm{K} \alpha$ line $(h v=1,486.71 \mathrm{eV})$.

The bonding structures of the films were investigated using micro-Raman spectroscopy having a $\mathrm{He}-\mathrm{Ne}$ laser $(632 \mathrm{~nm})$ over the range of $800-2,000 \mathrm{~cm}^{-1}$. Five measurements on each sample were carried out to get an averaged intensity ratio $\left(I_{\mathrm{D}} / I_{\mathrm{G}}\right)$.

The microstructure of the PtN-DLC films was observed using transmission electron microscopy (TEM, JEOL-JEM-2010).

The surface morphologies of the films were studied using atomic force microscopy (AFM) (Digital Instrument, S-3000) with a tapping mode $\mathrm{Si}_{3} \mathrm{~N}_{4}$ cantilever in a scan size of $1 \mu \mathrm{m} \times 1 \mu \mathrm{m}$ as well as scanning electron microscopy (SEM, JEOL-JSM-5600LV).

The tribological properties of the samples were investigated using a ball-on-disc micro-tribometer (CSM) at RT. A Cr6 steel ball of $6 \mathrm{~mm}$ in diameter was slid on each sample surface in a circular path of $4 \mathrm{~mm}$ in diameter for about $0.031 \mathrm{~km}$ at a sliding speed of $3 \mathrm{~cm} / \mathrm{s}$ under a normal load of $1 \mathrm{~N}$. Three measurements per sample were carried out to get an average friction coefficient. The widths and depths of wear tracks of the samples were measured using white light confocal imaging profilometry and averaged with 4 measurements per wear track.

\section{Results and discussion}

The chemical compositions of the PtN-DLC films deposited with different RF powers applied to the $\mathrm{Pt}$ target are presented in Fig. 1. The Pt content in the PtN-DLC films significantly increases from about 2.97 to 9.05 at\% with increased RF power applied to the $\mathrm{Pt}$ target from 20 to $60 \mathrm{~W}$. The $\mathrm{N}$ contents in all the films are in the range of 11.66 to 13.73 at $\%$. Increasing the Pt content in the PtN-DLC films increases the O content from 1.47 to 3.06 at $\%$ probably due to a greater difference in electronegativities between $\mathrm{O}(\sim 3.44$, pauling scale) and $\mathrm{Pt}(\sim 2.28)$ compared to that between $\mathrm{O}$ and $\mathrm{C}(\sim 2.55)$ [13]. 


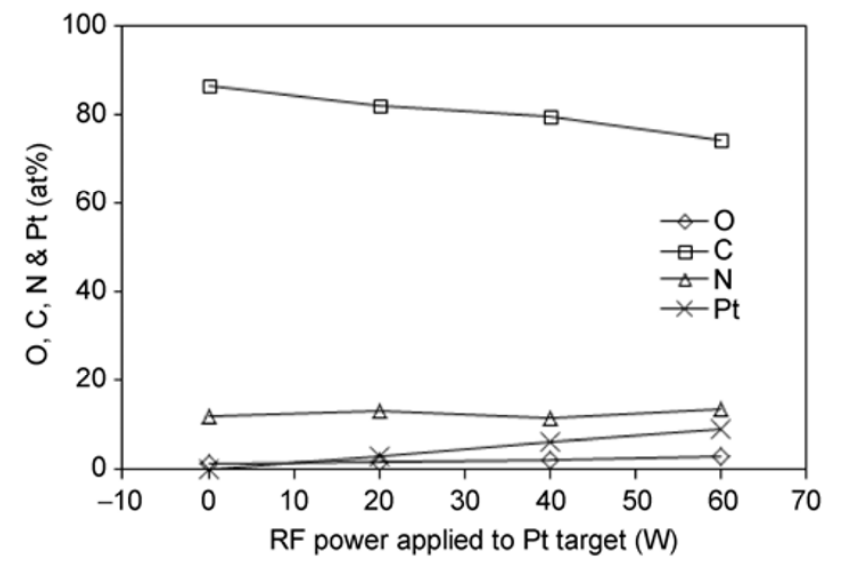

Fig. 1 Chemical compositions of PtN-DLC films deposited with different RF powers applied to Pt target.

Figure 2 shows the XPS spectrum of the PtN-DLC film deposited with the RF power of $60 \mathrm{~W}$ applied to the Pt target on which several peaks, such as $\mathrm{Pt} 4 \mathrm{f}, \mathrm{C} 1 \mathrm{~s}$, $\mathrm{Pt} 4 \mathrm{~d}, \mathrm{~N}$ 1s, O 1s, and $\mathrm{Pt} 4 \mathrm{~s}$, can be clearly identified.

Figure 3(a) shows the $C$ 1s spectra of the PtN-DLC films deposited with different RF powers applied to the $\mathrm{Pt}$ target. The $\mathrm{C}$ 1s peaks slightly shift to lower binding energies (285.1 to $284.7 \mathrm{eV}$ ) with an increase in the RF power ( 0 to $60 \mathrm{~W}$ ), indicating that the increased Pt content in the PtN-DLC films results in the increased amount of $\mathrm{sp}^{2}$ bonds in the films via metal-induced graphitization [6-9, 14-18]. Figure 3(b) illustrates the $\mathrm{N}$ 1s spectra of the PtN-DLC films deposited with different RF powers applied to the $\mathrm{Pt}$ target. The increased RF power applied to the $\mathrm{Pt}$ target does not significantly shift the $\mathrm{N} 1 \mathrm{~s}$ peaks of

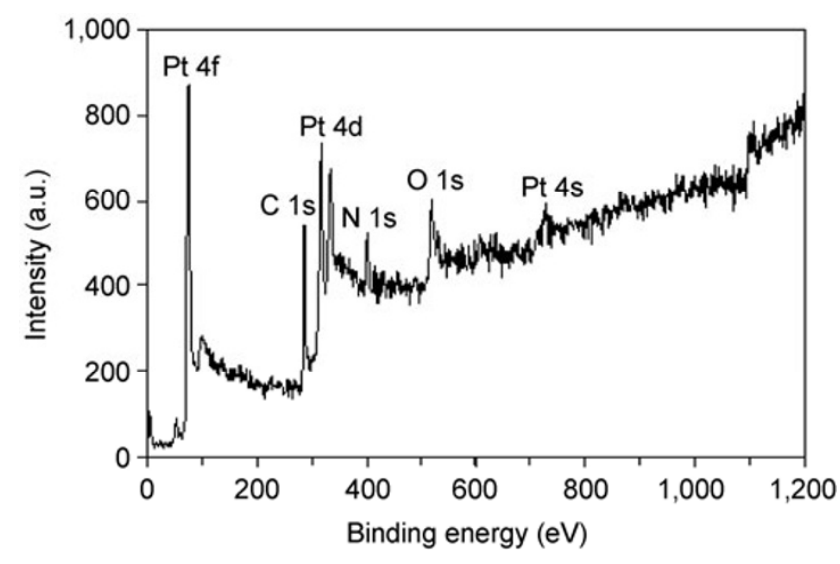

Fig. 2 XPS wide scan of PtN-DLC film deposited with RF power of $60 \mathrm{~W}$ applied to Pt target.

the PtN-DLC films to lower binding energies as the $\mathrm{N} 1$ s peaks exist at about $398.8 \mathrm{eV}$. Figure 3(c) shows the $\mathrm{Pt} 4 \mathrm{f}$ peaks of the PtN-DLC films deposited with different RF powers applied to the $\mathrm{Pt}$ target. The increased RF power applied to the $\mathrm{Pt}$ target slightly shift the spin-orbit coupling peaks of $\mathrm{Pt} 4 \mathrm{f}(7 / 2,5 / 2)$ to lower binding energies (71.4 to $71.1 \mathrm{eV})$ as a result of an increase in neutral $\mathrm{Pt}$ having lower binding energies and weaker extra Coulombic interactions with an increase in the Pt content [9].

The fitted Raman peaks with Gaussian G (graphite) and D (disorder) peaks of the PtN-DLC films deposited with different RF powers applied to the Pt target are presented in Fig. 4 [6-9, 14-18]. The intensities of the Raman peaks apparently decrease with increased RF power applied to the Pt target due
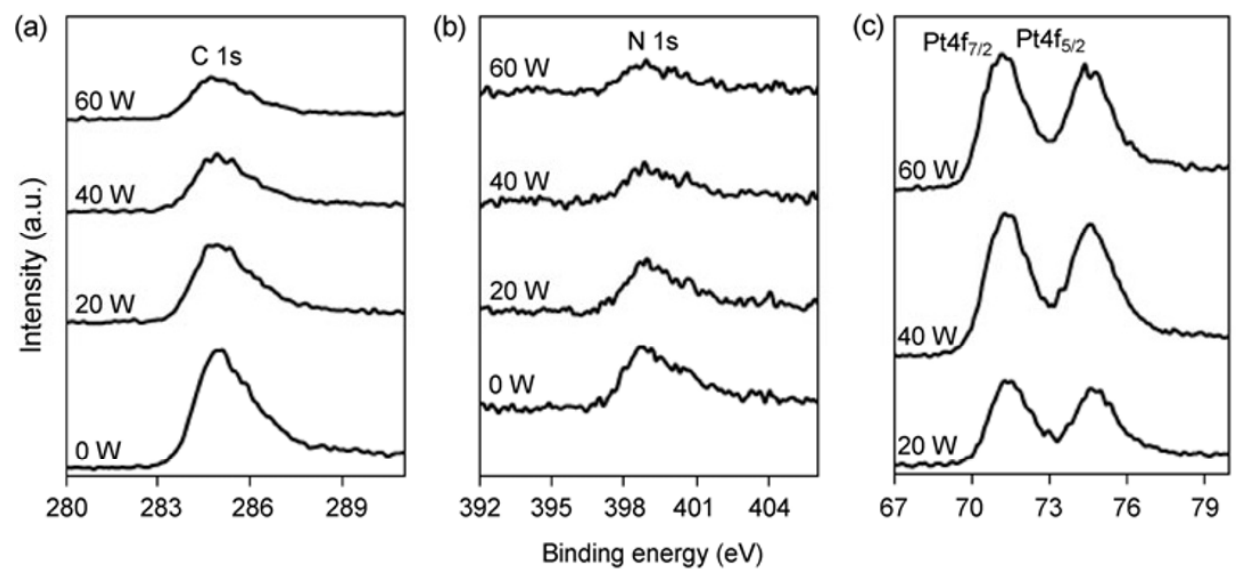

Fig. 3 XPS (a) C 1s, (b) N 1s, and (c) Pt 4f spectra of PtN-DLC films deposited with different RF powers applied to Pt target. 


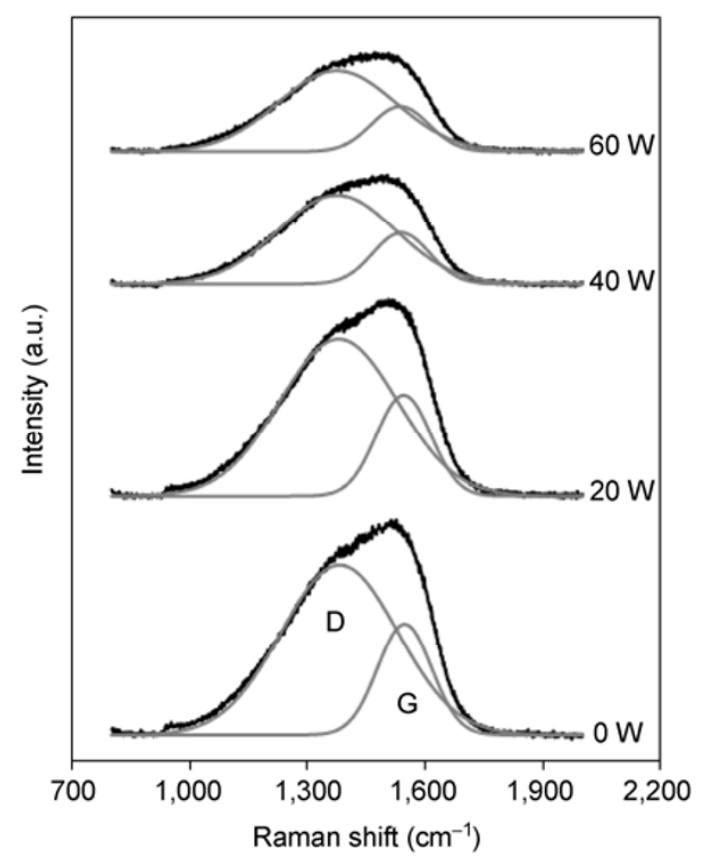

Fig. 4 Fitted Raman spectra of PtN-DLC films deposited with different RF powers applied to Pt target.

to the increased inactive phases that result from the undissolved $\mathrm{Pt}$ aggregates within the nitrogen doped amorphous carbon matrices $[8,9,18]$. The shapes of the Raman peaks become symmetrical with increased RF power applied to the $\mathrm{Pt}$ target by developing the D peaks [9].

Figure 5 illustrates the $I_{\mathrm{D}} / I_{\mathrm{G}}$ ratios of the PtN-DLC films deposited with different RF powers applied to the Pt target. An intensity ratio $\left(I_{\mathrm{D}} / I_{\mathrm{G}}\right)$ between the $D$ and $G$ peaks can give the information about the carbon bonding structure such as graphite clustering and structural disordering [6-9, 14-18]. The larger

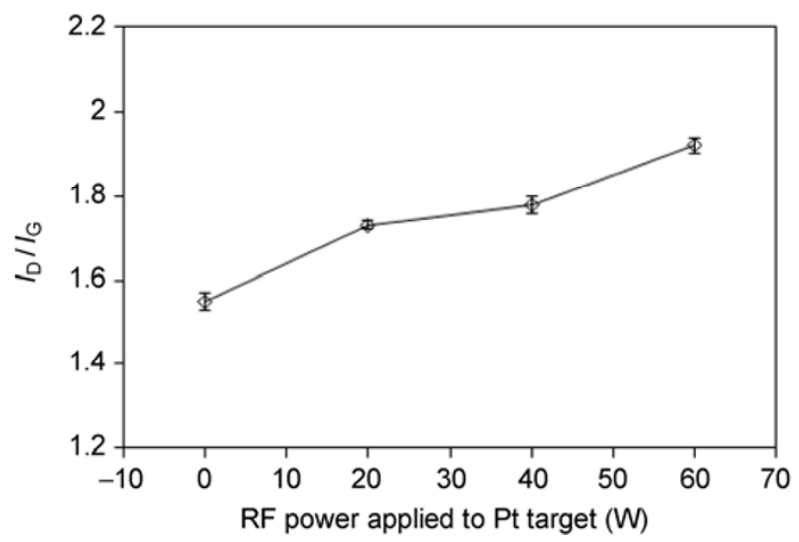

Fig. 5 Raman $\left(I_{\mathrm{D}} / I_{\mathrm{G}}\right)$ intensity ratios of PtN-DLC films deposited with different RF powers applied to Pt target.
$I_{\mathrm{D}} / I_{\mathrm{G}}$ ratio (about 1.73) of the PtN-DLC film deposited with the RF power of $20 \mathrm{~W}$ applied to the Pt target than that (about 1.55) of the N-DLC film indicates that the incorporation of $\mathrm{Pt}$ in the N-DLC film results in the metal-induced graphitization of the film [6-9, 14-18]. It is reported [6-9, 14-18] that metal phases can act as catalysts to enhance graphitization of amorphous carbon around them due to a high sputtered carbon energy. Normally, a sputtering process can provide sufficient energy to locally heat amorphous carbon on a metal surface according to a thermal spike mode [6-9, 14-18]. In addition, amorphous carbon contacting with metal phases can transform to graphite at a relatively low temperature [6-9, 14-18]. It is supposed that the incorporation of $\mathrm{Pt}$ during the sputtering process locally promotes $\mathrm{sp}^{2}$ bonds in the amorphous carbon matrix via metal-induced graphitization [6-9, 14-18]. Therefore, the increased RF power applied to the Pt target leads to the increased $I_{\mathrm{D}} / I_{\mathrm{G}}$ ratio of the PtN-DLC films through the enhanced metal-induced graphitization of the films as found in Fig. 5 [6-9, 14-18].

Figure 6 shows the TEM image of the PtN-DLC film deposited with the RF power of $60 \mathrm{~W}$ applied to the $\mathrm{Pt}$ target. An aggregation of $\mathrm{Pt}$ in the nitrogen doped amorphous carbon matrix is found and the sizes of the $\mathrm{Pt}$ aggregates are in the range of about 5 to $10 \mathrm{~nm}$.

Comparison of Figs. 7(a) and 7(b) clearly indicates that the surface asperities of the PtN-DLC film deposited with the RF power of $60 \mathrm{~W}$ applied to the

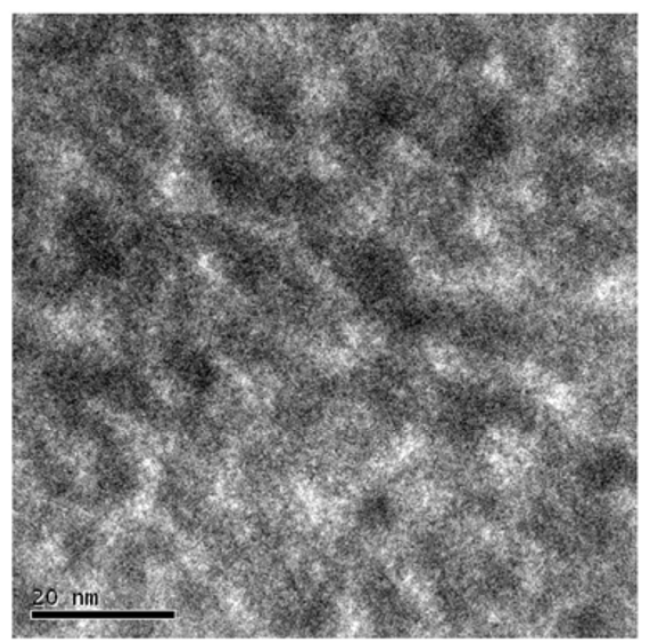

Fig. 6 TEM image of PtN-DLC film deposited with RF power of $60 \mathrm{~W}$ applied to Pt target. 

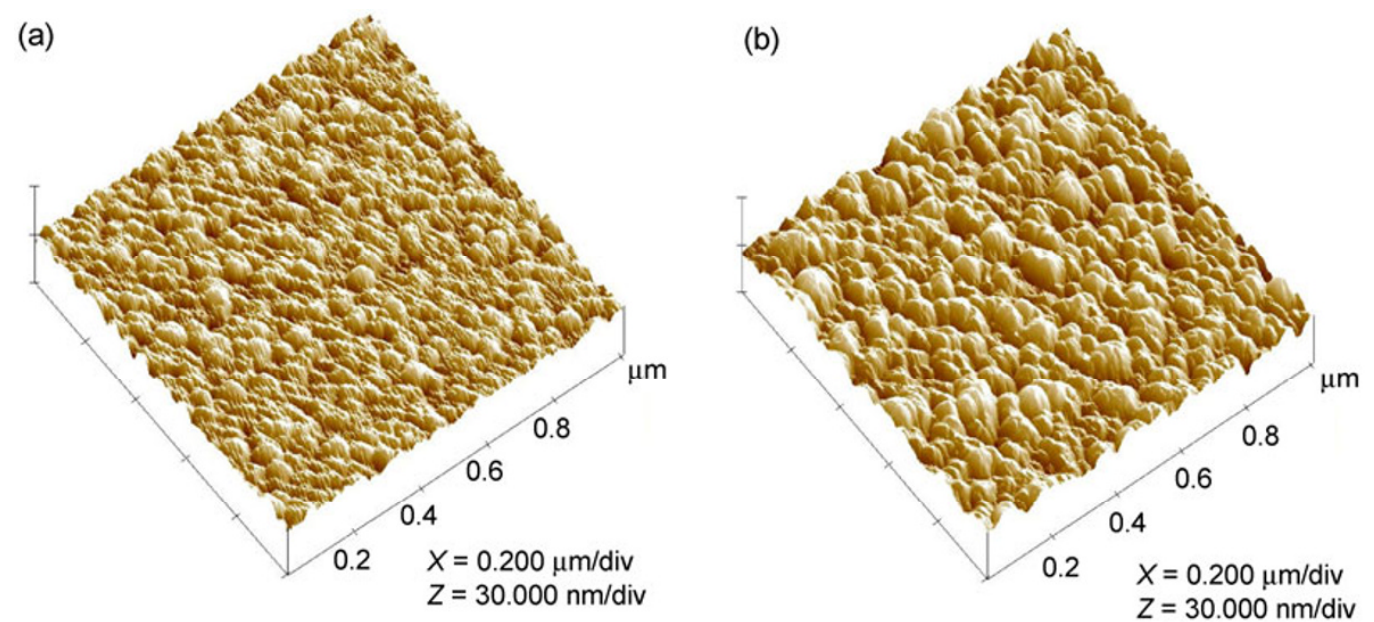

Fig. 7 AFM images showing surface topographies of (a) N-DLC film and (b) PtN-DLC film deposited with RF power of $60 \mathrm{~W}$ applied to Pt target.

Pt target are apparently larger than those of the $\mathrm{N}$-DLC film probably due to the incorporation of $\mathrm{Pt}$ particles and their aggregation (Fig. 6). It is clear that the incorporation of $\mathrm{Pt}$ in the N-DLC film gives rise to the higher surface roughness, which is confirmed by the larger $R_{\mathrm{a}}(\sim 2.1 \mathrm{~nm})$ of the PtN-DLC film $(60 \mathrm{~W})$ than that $(\sim 1.4 \mathrm{~nm})$ of the N-DLC film.

Figure 8(a) shows the friction coefficients of the $\mathrm{Si}$ substrate, N-DLC film, and PtN-DLC films deposited with different RF powers applied to the Pt target, slid against the steel balls for about $0.031 \mathrm{~km}$ at a sliding speed of $3 \mathrm{~cm} / \mathrm{s}$ under a normal load of $1 \mathrm{~N}$. The mean friction coefficient of the $\mathrm{Si}$ substrate is about 0.615 . However, coating of the Si substrate with the N-DLC film significantly reduces the mean friction coefficient to about 0.233 because the existence of the harder N-DLC film on the Si substrate effectively prevents the wear of the Si substrate $[10,19,20]$. In addition, the incorporation of $\mathrm{N}$ in the DLC film gives rise to a lubricating effect reducing the friction of the film during the sliding because nitrogen doping promotes graphitization of the film [3, 18, 21, 22]. Normally, a possible adhesion between two surfaces in contact elastically or plastically deforms materials around the contact junctions under a high normal load and gives rise to a high friction via effective interfacial shear strength between the two contacting surfaces $[10,19,20]$. It can be seen that the existence of the harder N-DLC film on the Si substrate reduces the adhesive friction by preventing elastic or plastic
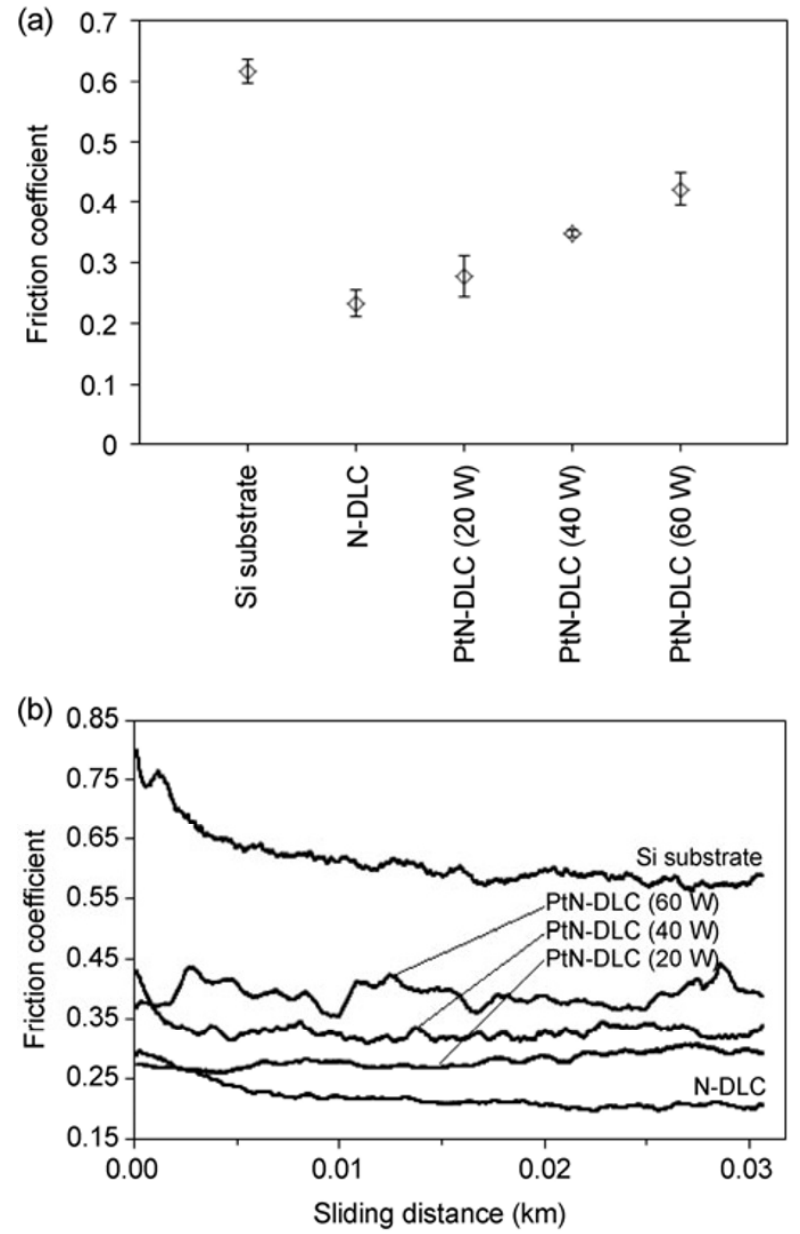

Fig. 8 (a) Friction coefficients of Si substrate, N-DLC film, and PtN-DLC films deposited with different RF powers applied to $\mathrm{Pt}$ target, slid against a steel ball of $6 \mathrm{~mm}$ in diameter in a circular path of $4 \mathrm{~mm}$ in diameter for about $0.031 \mathrm{~km}$ at a sliding speed of $3 \mathrm{~cm} / \mathrm{s}$ under a normal load of $1 \mathrm{~N}$. (b) Friction coefficients of the same samples as a function of sliding distance. 
deformation of materials around the contact junctions while the lubricating effect of the N-DLC film helps to decrease the adhesive friction by lessening the interfacial shear strength between the ball and film $[10,19,20]$.

The incorporation of $\mathrm{Pt}$ in the N-DLC film increases the friction of the film, which is confirmed by the higher mean friction coefficient (about 0.279) of the PtN-DLC film deposited with the RF power of $20 \mathrm{~W}$ applied to the Pt target than that of the N-DLC film as found in Fig. 8(a). Although the friction of the PtN-DLC film $(20 \mathrm{~W})$ should decrease with its promoted graphitization (Fig. 5), the increased friction of the PtN-DLC film clearly indicates that the influence of graphitization on the friction of the PtN-DLC film is not significant probably due to the stronger effect of incorporated $\mathrm{Pt}$ because the incorporation of $\mathrm{Pt}$ promotes the wear of the PtN-DLC film by degrading the $\mathrm{sp}^{3}$-bonded cross-linking structure of the film $[4,5,9,23,24]$. In addition, the lower elastic modulus of incorporated $\mathrm{Pt}$ aggregates and the larger number of $\mathrm{sp}^{2}$ bonds in the PtN-DLC film can result in the larger contact between the steel ball and film, and give rise to the higher friction of the film via the higher interfacial shear strength between the steel ball ball and film $[4,5,9]$. Since a rougher surface can give a higher friction via mechanical interlocking between two mating surface asperities, the increased surface roughness of the PtN-DLC film (20 W) (Fig. 7) contributes to the increased friction of the film (Fig. 8(a)) [10, 11]. Therefore, the further increased RF power applied to the $\mathrm{Pt}$ target from 40 to $60 \mathrm{~W}$ further increases the mean friction coefficient of the PtN-DLC films from about 0.348 to 0.421 as a result of the increased Pt content in the films (Fig. 8(a)). Nevertheless, the friction coefficients of the PtN-DLC coated Si substrates are significantly lower than that of the uncoated Si substrate, which clearly implies that the PtN-DLC films can effectively prevent their underlying Si substrates from wear.

Figure $8(\mathrm{~b})$ shows the friction coefficients of the Si substrate, N-DLC film, and PtN-DLC films as a function of sliding distance. Normally, the high wear resistance of DLC films results in a stable friction throughout wear test. In Fig. 8(b), the N-DLC film exhibits the most stable friction during the entire sliding among the films used in this study, which is indicative of the highest wear resistance of the N-DLC film. The fluctuations in the friction coefficients of the PtN-DLC films with respect to sliding distance become pronounced with increased Pt content. Since a fluctuation in the friction coefficient is related to an unstable wear, the results indicate that the incorporation of $\mathrm{Pt}$ results in the unstable wear of the PtN-DLC film during the sliding as the increased Pt content further decreases the wear resistance of the PtN-DLC films. In addition, the N-DLC film shows the lowest trend of friction coefficient versus sliding distance among the films as the PtN-DLC film with the higher Pt content has the higher trend of friction coefficient versus sliding distance. However, the trends of friction coefficient versus sliding distance of the N-DLC and PtN-DLC coated Si substrates are apparently lower than that of the uncoated Si substrate. It can be deduced that the N-DLC and PtN-DLC films can effectively prevent their underlying $\mathrm{Si}$ substrates from wear during the entire sliding although the higher Pt content gives rise to the lower wear resistance of the PtN-DLC films.

Figure 9 shows the wear results of the Si substrate, N-DLC film, and PtN-DLC films deposited with different RF powers applied to the Pt target. The repeated sliding of the steel ball on the $\mathrm{Si}$ substrate generates a significant wear track on the surface with the measurable wear width and depth of about 417.3

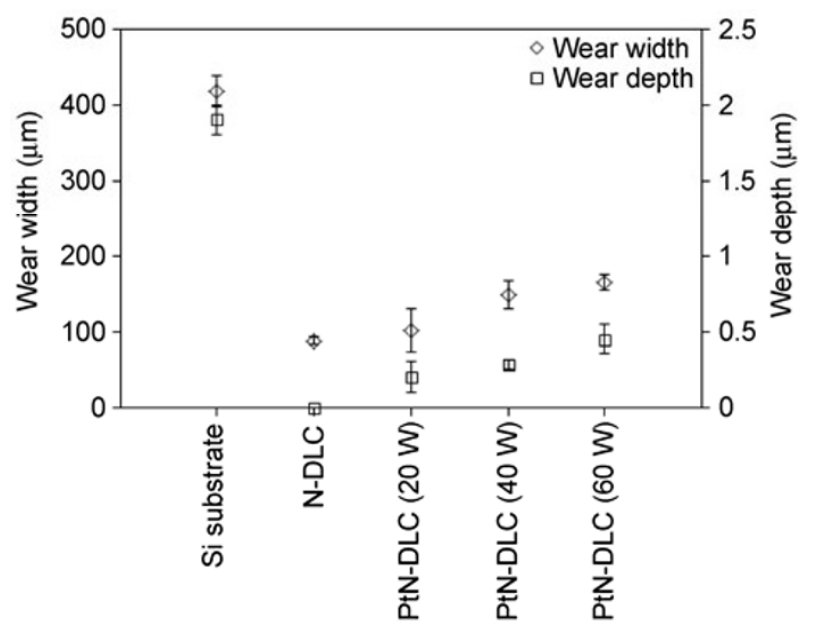

Fig. 9 Wear widths and depths of Si substrate, N-DLC film, and PtN-DLC films deposited with different RF powers applied to $\mathrm{Pt}$ target, slid under the same conditions as described in Fig. 8. 
and $1.9 \mu \mathrm{m}$, respectively. When the $\mathrm{Si}$ substrate is coated with the N-DLC film, the N-DLC film effectively prevents its $\mathrm{Si}$ substrate from wear so that a wear track is not apparently found on the surface of the N-DLC film. However, the incorporation of $\mathrm{Pt}$ in the N-DLC film reduces the wear resistance of the film, which is confirmed by the measurable wear width (about $101 \mu \mathrm{m}$ ) and depth (about $0.2 \mu \mathrm{m}$ ) of the PtN-DLC film deposited with the RF power of $20 \mathrm{~W}$ applied to the Pt target as found in Fig. 9. The reason is that the degraded $\mathrm{sp}^{3}$-bonded cross-linking structure of the PtN-DLC film associated with the incorporation of $\mathrm{Pt}$ is responsible for the reduced wear resistance of the film [4, 5, 9, 23, 24]. In addition, the wear width and depth of the PtN-DLC films further increase to about 165.4 and $0.45 \mu \mathrm{m}$, respectively, with further increased RF power applied to the Pt target to $60 \mathrm{~W}$, indicating that the increased Pt content in the PtN-DLC films decreases the wear resistance of the films. The significantly smaller wear widths and depths of the PtN-DLC coated Si substrates than those of the uncoated $\mathrm{Si}$ substrate clearly indicate that the PtN-DLC films can effectively prevent the underlying $\mathrm{Si}$ substrates from wear. The similar trends of the friction (Fig. 8(a)) and wear (Fig. 9) of the samples imply that the friction of the samples is closely related to their wear.

After the tribological test, the surfaces of the worn Si substrate, N-DLC film, and PtN-DLC films were observed using SEM. As found in Figs. 10(a) and 10(b),
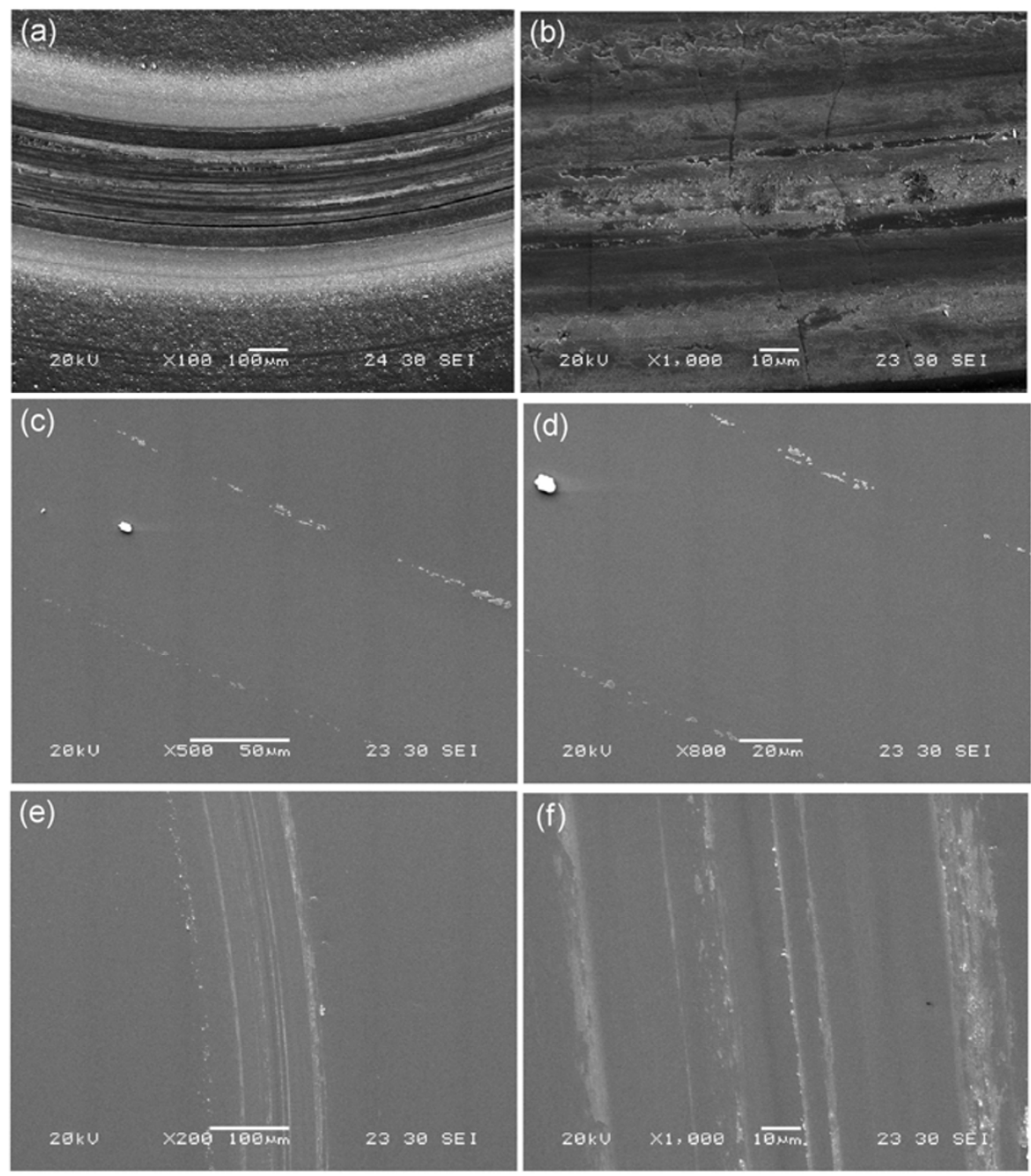

Fig. 10 SEM images showing surface morphologies of worn (a) and (b) Si substrate, (c) and (d) N-DLC film and (e) and (f) PtN-DLC film deposited with RF power of $60 \mathrm{~W}$ applied to the Pt target, slid under the same conditions as described in Fig. 8, observed at different magnifications. 
the repeated sliding of the steel ball on the Si substrate generates sever wear on the surface. In addition, abrasive lines on the wear track of the Si substrate (Fig. 10(a)) indicate that the wear of the Si substrate is attributed to the abrasive wear. In Fig. 10(b), microcracks initiated perpendicular to the sliding direction and propagated into the subsurface are apparently found on the wear track of the Si substrate, resulting from surface fatigue caused by cyclic stress concentration occurred in front of the steel ball under cyclic loading $[25,26]$. As found in Figs. 10(c) and 10(d), the N-DLC film does not show any significant wear, which confirms that the N-DLC film can effectively prevent its underlying $\mathrm{Si}$ substrate from wear. However, the significant wear track on the PtN-DLC film deposited with the RF power of $60 \mathrm{~W}$ applied to the Pt target (Figs. 10(e) and 10(f)) clearly indicates that the incorporation of $\mathrm{Pt}$ gives rise to the lower wear resistance of the PtN-DLC film compared to that of the N-DLC film. Comparison of Figs. 10(a) and 10(e) clearly confirms that the PtN-DLC film still can effectively prevent its underlying $\mathrm{Si}$ substrate from wear. Normally, DLC films could have poor adhesion onto their underlying substrates due to their high residual stresses [3-5]. As a result, the poor adhesion strength of DLC films would degrade their tribological performance via their adhesive failure during sliding [3-5]. However, no significant detachments of the N-DLC and PtN-DLC films from their Si substrates (Figs. 10(c)-(f)) imply that the adhesion strengths of the N-DLC and PtN-DLC films are strong enough to prevent the adhesive failure of the films during the sliding because the incorporation of $\mathrm{N}$ or both $\mathrm{N}$ and $\mathrm{Pt}$ reduces the residual stress of the films by increasing the $\mathrm{sp}^{2}$ bonds, degrading the $\mathrm{sp}^{3}$-bonded cross-linking structures, and consequently promotes the adhesion of the films to their Si substrates. The SEM observation clearly shows that the N-DLC and PtN-DLC films can effectively prevent their $\mathrm{Si}$ substrates from wear without any significant adhesive failure although the incorporation of $\mathrm{Pt}$ reduces the wear resistance of the PtN-DLC films.

\section{Conclusions}

In this study, the effects of Pt content on the tribological properties of PtN-DLC films deposited on Si substrates with different RF powers applied to the Pt target during the sputtering depositions were systematically investigated. The uncoated $\mathrm{Si}$ substrate slid against the steel ball exhibited severe abrasive and fatigue wear. The N-DLC film effectively prevented its underlying Si substrate from wear so that no obvious wear track was found on the N-DLC film coated sample. However, significant wear tracks were found on the PtN-DLC films, which was indicative of the reduced wear resistance of the PtN-DLC films with the incorporation of $\mathrm{Pt}$ because the $\mathrm{Pt}$ aggregation and the metal-induced graphitization degraded the $\mathrm{sp}^{3}$-bonded cross-linking structures of the PtN-DLC films. As a result, the increased $\mathrm{Pt}$ content in the PtN-DLC films decreased the wear resistance of the films. The tribological results clearly showed that both the N-DLC and PtN-DLC films could effectively protect the underlying $\mathrm{Si}$ substrates from wear though the wear resistance of the PtN-DLC films was lower than that of the N-DLC film.

Open Access: This article is distributed under the terms of the Creative Commons Attribution License which permits any use, distribution, and reproduction in any medium, provided the original author(s) and source are credited.

\section{References}

[1] Priest M, Taylor C M. Automobile engine tribologyapproaching the surface. Wear 241: 193-203 (2000)

[2] Saha B, Liu E, Torr S B, Khun N W, Hardt D E, Chun J H. Anti-sticking behavior of DLC coated silicon micromolds. $J$ Micromech Microeng 19: 105025 (2009)

[3] Khun N W, Liu E, Zeng X T. Corrosion behavior of nitrogen doped diamond-like carbon thin films in $\mathrm{NaCl}$ solutions. Corro Sci 51: 2158-2164 (2009)

[4] Khun N W, Liu E. Cyclic voltammetric behavior of nitrogendoped tetrahedral amorphous carbon films deposited by filtered cathodic vacuum arc. Electroanalysis 20: 1851-1856 (2008)

[5] Khun N W, Liu E. Enhancement of adhesion strength and corrosion resistance of nitrogen or platinum/ruthenium/nitrogen doped diamond-like carbon thin films by platinum/ruthenium layer. Diam Rel Mater 19: 1065-1072 (2010)

[6] Qi G J, Zhang S, Tang T T, Li J F, Sun X W, Zeng X T. Experimental study of aluminum-induced crystallization of 
amorphous silicon thin films. Surf Coat Tech 198: 300-303 (2005)

[7] Bewilogua K, Wittorf R, Thomsen H, Weber M. DLC based coatings prepared by reactive d.c. magnetron sputtering. Thin Solid Films 447-448: 142-147 (2004)

[8] Pleskov Y V, Evstefeeva Y E, Baranov A M. Threshold effect of admixtures of platinum on the electrochemical activity of amorphous diamond-like carbon thin films. Diam Relat Mater 11: 1518-1522 (2002)

[9] Khun N W, Liu E, Yang G C, Ma W G, Jiang S P. Structure and corrosion behavior of platinum/ruthenium/nitrogen doped diamondlike carbon thin films. J Appl Phys 106: 013506 (2009)

[10] Khun N W, Liu E. Investigation of structure, adhesion strength, wear performance and corrosion behavior of platinum/ruthenium/nitrogen doped diamond-like carbon thin films with respect to film thickness. Mater Chem Phys 126: 220-226 (2010)

[11] Khun N W, Liu E, Yang G C. Structure, scratch resistance and corrosion performance of nickel doped diamond-like carbon thin films. Surf Coat Technol 204: 3125-3130 (2010)

[12] Khun N W, Liu E. Corrosion behavior of aluminum doped diamond-like carbon thin films in $\mathrm{NaCl}$ aqueous solution. $J$ Nanosci Nanotechnol 10: 4767-4772 (2010)

[13] Quagliano J V. Chemistry, $2^{\text {nd }}$ Ed. Japan, 1963.

[14] Lee C S, Kim T Y, Lee K R, Yoon K H. Nanoscale manipulation of tetrahedral amorphous carbon films. Thin Solid Films 447-448: 169-173 (2004)

[15] Hofsass H, Feldermann H, Merk R, Sebastian M, Ronning C. Cylindrical spike model for the formation of diamondlike thin films by ion deposition. Appl Phys A 66(2): 153-181 (1998)

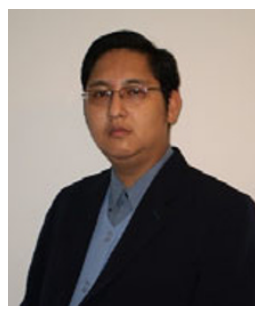

Nay Win KHUN. He received his MS degree in "Mechanics and Processing of Materials" in 2006 and his PhD degree in "Thin Films Physics and Electrochemistry" in

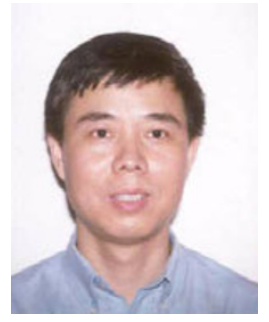

Erjia LIU. He received his $\mathrm{PhD}$ degree in metallurgy and materials engineering from Katholieke Universiteit Leuven, Belgium. He is currently an associate professor
[16] Oya A, Otani S. Catalytic graphitization of carbons by various metals. Carbon 17: 131-137 (1979)

[17] Corbella C, Bertran E, Polo M C, Pascual E, Andujar J L. Structural effects of nanocomposite films of amorphous carbon and metal deposited by pulsed-DC reactive magnetron sputtering. Diam Relat Mater 16: 1828-1834 (2007)

[18] Robertson J. Diamond-like amorphous carbon. Mate Sci Eng R 37: 129-281 (2002)

[19] Mate C M. Tribology on the Small Scale: A Bottom up Approach to Friction, Lubrication and Wear, $1^{\text {st }}$ Ed. Oxford University Press, US, 2008.

[20] Ronkainen H, Laukkanen A, Holmberg K. Friction in a coated surface deformed by a sliding sphere. Wear 263: 1315-1323 (2007)

[21] Khun N W, Liu E. Investigation of corrosion behavior of nitrogen doped and platinum/ruthenium doped diamond-like carbon thin films in Hank' s solution. Mater Sci Eng C 31: 1539-1544 (2011)

[22] Wei J, Hing P, Mo Z Q. Structure and tribological behaviour of carbon nitride films. Wear 225-229: 1141-1147 (1999)

[23] Ta M, Hu Z Y, Wang H, Li X. Microstructural and stress properties of ultrathin diamondlike carbon films during growth: Molecular dynamics simulations. Phys Rev B 75(3): 035425 (2007)

[24] Tan A H, Chen Y C. Optimization of wear-corrosion properties of a-C:N films using filtered cathodic arc deposition. Diam Relat Mater 17: 36-42(2008)

[25] Tabor D. Surface forces and surface interactions. J Colloid Interface Sci 58: 2-13 (1977)

[26] Xing X S, Li R K Y. Wear behavior of epoxy matrix composites filled with uniform sized sub-micron spherical silica particles. Wear 256: 21-26 (2004)

2011, both from the Nanyang Technological University, Singapore. His research interests include composite materials, thin films, coatings, tribology, corrosion, surface, and interface.

with the School of Mechanical and Aerospace Engineering, Nanyang Technological University, Singapore. His research interests include thin films, coatings, carbon materials, nanocomposites, nanotribology, nanomechanics, and electrochemistry. 